\title{
AS OLIGARQUIAS POLÍTICAS DA PARAÍBA E O INGRESSO DAS MULHERES NOS ESPAÇOS DE PODER - O CASO DA SENADORA DANIELLA RIBEIRO
}

\author{
Elizabeth Christina de Andrade Lima ${ }^{1}$ \\ Michelly Pereira de Sousa Cordão ${ }^{2}$
}

\begin{abstract}
RESUMO: Artigo trata da continuidade do poder dos grupos oligárquicos no Estado da Paraíba. Como caso para análise, tomamos como exemplo, a família Ribeiro, hoje representada por sua figura mais ilustre: a Senadora da República, Daniella Velloso Borges Ribeiro. Tal grupo familiar exerce seu poder na cidade de Campina Grande, Estado da Paraíba, há pelo menos quarenta anos, e de lá pra cá vem se perpetuando a partir do avô, Enivaldo Ribeiro, "chefe do clã" dos Ribeiro; da avó, Virgínia Veloso Ribeiro; do filho, Aguinaldo Ribeiro; da filha, Daniella Ribeiro e do neto, Lucas Ribeiro. Ou seja, três gerações de descendentes se alternando no poder local, seja nos poderes Executivo, seja no Legislativo. Tais membros já exerceram ou exercem as funções de Prefeito, vice-Prefeito, Vereador, Deputado Estadual, Deputado Federal, Senador e Ministro de Estado. Ou seja, já ocuparam cargos nas esferas municipal, estadual e federal. O que demonstra não só a longevidade, mas a força política desse grupo familiar. Nosso intento é descrever sobre a ascensão política da hoje Senadora Daniella Ribeiro e de como ela construiu a sua "carreira" política a partir da influência e apoio de seu grupo familiar. Para tanto, realizamos entrevista aberta e semi-estruturada com Daniella Ribeiro, que a época exercia o mandato de Deputada Estadual, e que gentilmente nos recebeu em seu gabinete na Assembleia Legislativa, no dia 13 de fevereiro de 2017.
\end{abstract}

Palavras-Chave: Oligarquias; Mulher e Política; familismo.

\section{THE POLITICAL OLIGARKIES OF PARAÍBA AND WOMEN'S ENGAGEMENT IN POWER AREAS - THE CASE OF MS. DANIELA RIBEIRO}

\begin{abstract}
This article deals with the continuity of the power of the oligarchic groups in the State of Paraíba. As a case for analysis, we take as an example, the Ribeiro family, today represented for her most illustrious figure: Senator Daniella Velloso Borges Ribeiro. This family group exercises its power in the city of Campina Grande, State of Paraíba, for at least forty years, and since then has been perpetuating from the grandfather, Enivaldo Ribeiro, "clan chief" of the Ribeiro; from her grandmother, Virginia Veloso Ribeiro; of the son, Aguinaldo Ribeiro; daughter Daniella Ribeiro and grandson Lucas Ribeiro. That is, three generations of alternating in local power, whether in the Executive or Legislative. Such members have previously held or are serving as mayor, vice mayor, Councilman, State Representative, Federal Deputy, Senator and Minister of State. That is they have held positions at the municipal, state and federal levels. Which demonstrates not only the longevity, but the political strength of this family group. Our intention is to describe about the political rise of today's Senator Daniella Ribeiro and how she built her Political "career" from the influence and support of her family group. Therefore, we conducted an open and semi-structured interview with Daniella Ribeiro, who at the time served as State Deputy, and who kindly received us in her office at Legislative Assembly on February 13, 2017.
\end{abstract}

Keywords: Oligarchies; Women and Politics; Familism.

\footnotetext{
${ }^{1}$ Professora Titular de Antropologia da Universidade Federal de Campina Grande - PB. Doutora. ecalima@terra.com.br ${ }^{2}$ Professora Adjunto de História da Universidade Federal de Campina Grande - PB, Doutora. michellycordao@ gmail.com
} 


\section{INTRODUÇÃO}

A autoridade de um poder ou a dominação de um grupo depende do crédito outorgado ou recusado às representações que proponham de si mesmos. CHARTIER, 2009, p.50

Viemos morar na cidade de Campina Grande no ano de 1979, à época, o prefeito da cidade era Enivaldo Ribeiro, nascido em 26 de março de 1935; ele é o chefe do clã da família Ribeiro. Seus filhos, Aguinaldo Ribeiro e Daniella Velloso Borges Ribeiro, despontam atualmente no cenário político brasileiro, ambos do Partido Progressista - PP, e assumem, respectivamente, os cargos de Deputado Federal e Senadora da República.

Lá se foram 40 anos de nossa chegada a "Rainha da Borborema"3 e o grupo político dos Ribeiro já detinha seu poder na cidade, isso sem falar na esposa do chefe do clã, Virgínia Veloso Ribeiro, que já foi, por duas vezes, prefeita da cidade de Pilar, também no Estado da Paraíba. Daniella Ribeiro ingressa na vida pública no ano de 2004, antes, seu irmão, Aguinaldo, já tinha sido Deputado Estadual e Federal e seu pai, prefeito, deputado federal e atualmente é vice-prefeito de Campina Grande. Para não perder "a tradição" de continuidade na política, por parte dos descendentes dos Ribeiro, o filho de Daniella, Lucas Ribeiro, no ano de 2010, é eleito vereador pela cidade de Campina Grande. Em entrevista concedida ao Jornal da Paraíba, com o título: "filhas seguem exemplos das mães na Política Paraibana", de 14/05/2017, Lucas afirmou que "cresceu vendo e acompanhando seu avô Enivaldo nas suas campanhas". E acrescentou: "Ele sempre foi o referencial de política na nossa família. Nunca pensei em ingressar na vida pública até que em 2004 minha mãe entrou na política e começou a desempenhar um trabalho admirável e inspirador que vem fazendo até hoje. Foi onde nasceu o meu desejo de participar e atuar na vida pública.” (Jornal da Paraíba, 14/05/2017)

E assim a saga do clã Ribeiro continua a cada dia mais firme e forte, seja pela ocupação de cargos estratégicos na vida política do Estado e do País, seja no ingresso de seus descendentes para darem continuidade ao grupo oligárquico, por eles representado. $\mathrm{O}$ intento deste artigo é descrever a saga da família Ribeiro protagonizado por um de seus mais eminentes membros: a atual Senadora da República, Daniella Ribeiro. Apresentar a sua trajetória política e os discursos por ela utilizados para justificar tal inserção, a partir do uso do "nome de família" e trajetória de seu grupo familiar, é o que passamos a descrever. Para tanto, realizamos entrevista com a hoje Senadora e, à época, Deputada Estadual, no dia 13 de fevereiro de 2017, em seu gabinete na Assembleia Legislativa da Paraíba.

\footnotetext{
${ }^{3}$ Codinome dado a cidade de Campina Grande.
} 
Por se tratar de um artigo que tem como objeto as representações em torno de grupos de base familiar, apresentamos, inicialmente, algumas reflexões em torno das relações entre família e poder político. Tendo como tema central a questão das práticas e representações do poder em uma cidade do interior do Nordeste brasileiro, esperamos que este artigo possa contribuir também para ampliar os debates em torno do poder local.

\section{PODER POLÍTICO DE BASE FAMILIAR}

A temática da relação entre poder político e família tem sido abordada há décadas e hoje é possível contar com inúmeros trabalhos e toda uma tradição acadêmica que se traduz em produções sociológicas, antropológicas e historiográficas em torno deste tema ${ }^{4}$. De modo geral, estes trabalhos tem apontado a importância da família nas estruturas do poder político ao longo de toda a história brasileira. Rego (2008), por exemplo, afirma que a família representou papel essencial no estabelecimento das estruturas sobre as quais foi construído o estado brasileiro e que a família é tão indissociável das estruturas de poder no Brasil, que estudá-la é estudar essas mesmas estruturas. Exageros à parte, esta postura ajuda, ao menos, a chamar a atenção para as relações entre família e poder político.

Desde já cabe observar que nos limites deste artigo não adotaremos o conceito de coronelismo para explicar a relação entre família e poder político local, pois um fato que se tornou lugar comum na produção acadêmica, seja ela historiográfica ou mesmo sociológica, é relacionar o poder local e a interpretação da longevidade de algumas famílias ou grupos no controle político como a permanência, embora sob nova roupagem, do coronelismo. Isto é o que questiona criticamente, por exemplo, Adilson Filho:

Ao estudar a longevidade de algumas famílias no exercício do poder municipal [...] percebemos que muitos trabalhos caminham no sentido de traduzir tal realidade como a permanência do coronelismo, ou melhor, da sua capacidade de adaptação a diferentes situações históricas. (ADILSON FILHO, 2009, p.56)

\footnotetext{
${ }^{4}$ Conferir, entre outros: LEWIN, Linda. Política e Parentela na Paraíba: Um estudo de caso da oligarquia de base familiar. Rio de Janeiro: Record, 1993; LEMENHE, Maria Auxiliadora. Família, Tradição e Poder: o (caso) dos coronéis. São Paulo: Annablume/Edições UFC, 1995; FORTUNATO, Maria Lucinete. O Conceito de Coronelismo e a imagem do coronel: De símbolo a simulacro do poder local. Campina Grande, EDUFCG, 2008; RÊGO, André Heráclio do. Família e Coronelismo no Brasil: uma história de poder. São Paulo: A Girafa Editora, 2008; ADILSON FILHO, José. A Cidade Atravessada. Velhos e novos cenários da política belo-jardinense. Recife, Comunigraf Editora, 2009 e MONTEIRO, José Marciano. A Política como Negócio de Família. Para uma sociologia política das elites e do poder político familiar. São Paulo, LiberArs, 2016.
} 
A opção pela não utilização do conceito de coronelismo se deve ao fato de considerarmos inadequada a utilização deste conceito em períodos históricos anteriores ou posteriores à chamada Primeira República (1889-1930). Isto porque, em nossa concepção, formulada a partir das contribuições de Carvalho (1997), que por sua vez adota a perspectiva clássica proposta por Victor Nunes Leal acerca deste conceito, o coronelismo foi um sistema político que envolvia compromissos recíprocos entre os governos federal, estadual e municipal. Tal sistema é situado historicamente na primeira república e surge da convergência de uma conjuntura econômica com um fato político: a conjuntura econômica é a decadência dos fazendeiros e o fato político o federalismo implantado na Primeira República. Desta forma, este sistema não existiu antes da proclamação da república e não continuou a existir depois da chamada Revolução de 1930, que pôs fim ao federalismo existente até então.

Segundo Carvalho (1997), a insistência na permanência do coronelismo, que caracteriza parte da produção acadêmica ligada ao poder local, aponta para uma confusão conceitual: confunde-se mandonismo e clientelismo - práticas que atravessam praticamente toda a história brasileira e que não são incompatíveis com os signos do moderno e mesmo com os processos de modernização nas ambivalentes posturas e estratégias adotadas pelos políticos brasileiros ${ }^{5}-\operatorname{com}_{\text {o coronelismo e, em }}$ consequência dessa confusão, os políticos que se utilizam dessas práticas são vistos como coronéis. Neste sentido o referido autor procura definir, de forma mais precisa, os três conceitos. Procuremos, então, acompanhar o seu raciocínio.

Como já salientada a concepção de Carvalho (1997), acerca do coronelismo, apresento a forma como este autor define o mandonismo: este conceito

refere-se à existência local de estruturas oligárquicas e personalizadas de poder. O mandão, o potentado, o chefe, ou mesmo o coronel como indivíduo, é aquele que, em função do controle de algum recurso estratégico, em geral a posse da terra, exerce sobre a população um domínio pessoal e arbitrário que a impede de ter acesso ao mercado e à sociedade política. (CARVALHO, 1997, p.03)

Nesta formulação do conceito o mandonismo, no entanto, não é um sistema, é uma característica da política tradicional. Ele atravessa toda a história da colonização e do império, sobrevivendo, ainda hoje, em regiões isoladas. Porém, segundo o citado autor, a tendência é que desapareça completamente à medida em que os direitos civis e políticos alcancem todos os cidadãos;

$\mathrm{Na}$ visão de Leal, o coronelismo seria um momento particular do mandonismo, exatamente aquele em que os mandões começam a perder força e tem de recorrer ao governo. Mandonismo, segundo ele sempre existiu. É uma característica do coronelismo, assim como o é o clientelismo. (CARVALHO, 1997, p.03)

\footnotetext{
${ }^{5}$ A discussão e análise destas questões encontra-se em ADILSON FILHO, Op. Cit.
} 
Parte da produção acadêmica em torno do poder local identifica coronelismo e mandonismo. Segundo Carvalho (1997), esta produção contribuiu para esclarecer o fenômeno do mandonismo, no entanto

O fato de esta literatura ter tornado sinônimos os conceitos de coronelismo e mandonismo foi negativo. Alguns autores encontram mesmo um coronelismo urbano, ou um coronelismo sem coronéis (BANCK, 1974 apud CARVALHO, 1979, p.03).

Outro conceito que tem sido confundido com coronelismo é o de clientelismo. Este conceito indica um tipo de relação entre atores políticos que envolve a troca de benefícios como empregos, isenções fiscais, entre outros, por apoio político, principalmente na forma de voto. O clientelismo também não constitui um sistema, mas uma prática, ele, assim como o mandonismo, atravessa quase toda a história do país. No entanto, o clientelismo não segue uma trajetória sistematicamente decrescente como o mandonismo, ele pode aumentar ou diminuir ao longo da história, de acordo com o sistema político.

Ainda segundo Carvalho (1997), os autores que veem coronelismo no meio urbano e em fases recentes da história do Brasil estão simplesmente falando de clientelismo. Contudo, as relações clientelísticas, nos casos acima citados, dispensam a figura do coronel. Para finalizar esta questão da inadequação do conceito de coronelismo para a análise do poder local fora do período da chamada Primeira República, leia-se um exemplo dado pelo citado autor acerca da situação de uma cidade

\begin{abstract}
que na década de 60 era dominada por duas famílias, cujo poder baseava-se simplesmente na capacidade de barganhar empregos e benefícios públicos em troca de votos (Carvalho, 1966). As famílias não tinham recursos próprios, como os coronéis, e o fenômeno não era sistêmico, embora houvesse vínculos estaduais e federais. Por vários anos as duas famílias mantiveram o controle político da cidade, alternando-se no poder. Os resultados eleitorais eram previstos de antemão com precisão quase matemática. Os votos tinham dono, eram de uma ou de outra família. Tratava-se de um caso exacerbado de clientelismo político exercido num meio predominantemente urbano. Não se tratava de coronelismo. (CARVALHO, 1997, p.03)
\end{abstract}

Por outro lado, além desta inadequação - em termos da própria definição do conceito adotada neste artigo - do uso da noção de coronelismo em análises acerca do poder local fora do período da chamada Primeira República, também consideramos limitada a concepção de poder que norteia parte dos trabalhos que interpretam a longevidade de famílias ou grupos no controle político de alguns municípios como a permanência do coronelismo.

Isto porque, nestes casos, o poder local é visto quase sempre como um poder discricionário que pertence exclusivamente ao coronel e, desta forma, como também defendemos, estes trabalhos tem enfatizado a dominação em detrimento da forma como os atores sociais representam o universo político e, consequentemente, de como orientam suas práticas em meio às relações de poder. 
Adotamos, a parir do exposto, a ideia de que as oligarquias políticas tem se perpetuado no poder, em grande parte, a partir do nome de família, daquilo que Marciano Monteiro (2017) tem denominado de capital político familiar, ou seja, de toda uma construção simbólica, discursiva e prática que permite a perpetuação dos membros de uma mesma linhagem familiar se sucedendo no poder.

Isso explicaria, em parte, a continuidade, cada vez mais forte, da família Ribeiro no poder local, poder este concentrado de forma muito contundente nas mãos da filha da "chefe do clã", Daniella Ribeiro. Passemos agora a refletir sobre sua inserção na vida pública e a consequente continuidade desse grupo familiar no poder.

\section{A INSERÇÃO DAS MULHERES NA POLÍTICA PELA VIA FAMILIAR}

A atual Senadora da República Daniella Veloso Borges Ribeiro, nasceu em Campina Grande, na Paraíba, no dia 26 de março de 1972. É filha do Ex-Deputado Federal, Ex-Prefeito de Campina Grande e atual vice-Prefeito de Campina Grande, Enivaldo Ribeiro e de Virgínia Velloso Borges, ExPrefeita por duas vezes do município de Pilar, também no Estado da Paraíba e irmã do atual Deputado Federal e Ex-Ministro das Cidades, Aguinaldo Ribeiro. É formada em Pedagogia pela Universidade Federal da Paraíba (UFPB), foi professora e fez pós-graduação em Relações Internacionais na Universidade de Brasília (UnB). Desde pequena é engajada no mundo da política quando, muitas vezes, acompanhava seu pai nos eventos políticos.

A primeira disputa eleitoral de Daniella Ribeiro foi quando se candidatou a Vice-Prefeita de Campina Grande, no ano de 2004, embora não tenha logrado êxito. A disputa seguinte foi para candidatar-se ao cargo de Vereadora de Campina Grande, em 2008, sendo eleita com 6.838 votos (3,10\%). Em 2010 assume o seu primeiro mandato na Assembleia Legislativa da Paraíba, sendo eleita Deputada Estadual com 29.863 votos (1,5\%). Em 2012, licencia-se de seu mandato para concorrer ao mandato de prefeita da cidade de Campina Grande, mas não logrou êxito. Em 2014, foi reeleita Deputada Estadual da Paraíba com 46.938 votos (2,35\%) e em 2018, foi eleita Senadora da República com uma vitória "de virada", desbancando um dos principais candidatos, representante do clã da Família Cunha Lima, Cássio Rodrigues da Cunha Lima. A vitória de Daniella Ribeiro foi uma surpresa até para as agências de intenção de votos que nunca a apresentaram como favorita do eleitor para sair vitoriosa. Venceu, em segundo lugar, com $24,25 \%$ dos votos válidos, junto com o outro representante da Paraíba, este também representante do clã da Família Vital do Rêgo, Veneziano Vital do Rêgo. 
Ela carrega consigo o título de primeira mulher a representar o Estado da Paraíba no Senado Federal. Atualmente é líder do Partido Progressista no Senado, presidente da Comissão Mista de Combate à Violência contra a Mulher, tesoureira da União Interparlamentar e membro das seguintes Comissões no Senado: Assuntos Econômicos, Ciência e Tecnologia, Constituição e Justiça e Desenvolvimento Econômico.

As relações e práticas de poder influenciam deveras nos espaços articulados com a arena política. A inclusão ou não de determinada pessoa nesse espaço perpassa por um viés educativo e de reconstrução da identidade do que é ser homem e do que é ser mulher.

Embora as mulheres não tenham, em períodos passados, a visibilidade e notoriedade merecidas, elas sempre estiveram nos bastidores dos palcos da política. Sem dúvida, os papéis sociais e naturais relacionados ao cuidado, à maternidade e a outros atributos conexos, muitas vezes, se apresentam como obstáculos ao acesso a esses espaços de poder, acesso esse que se apresentou sempre muito restrito às mulheres. Dessa maneira, fica a indagação acerca da gênese da inserção dessas mulheres na política. Através de quais caminhos ou brechas as mulheres começaram a disputar os espaços de poder? Pela via familiar? Pela via dos movimentos sociais e feminismo? Pela inserção pública independente?

Para Rabay e Carvalho (2010), alguns estudos têm dado visibilidade à família como uma forma de ingresso das mulheres na disputa política partidária, principalmente no que diz respeito ao Nordeste, uma região com forte ênfase na instrumentalização das “mulheres de família” por parte das oligarquias, visando, sobretudo, à perpetuação no poder;

[...] a maioria das mulheres está ligada a esquemas eleitorais viciados e guarda relações de parentesco (era esposa, irmão ou filha) com algum político expressivo no cenário local. Além disso, utilizou estereótipos femininos para se eleger - a mãe sofredora, a benfeitora, a boa esposa, entre outros - indicando que uma retórica de manipulação da identidade feminina tradicional pode gerar dividendos políticos (RABAY \& CARVALHO, 1996, p.207).

Já para Costa (1998), as mulheres são chamadas na ausência ou por impedimento de um homem mais apto, com mais prestígio e mais confiável. Logo, a sua inclusão pela via familiar seria um reflexo da influência e predominância do poder patriarcal. Tudo leva a crer que as mulheres ao serem inseridas pela via familiar, apresentam-se como uma estratégia dos grandes partidos conservadores do que propriamente para exercer um papel diferenciado no cenário político e/ou por iniciativa próprias, pelo desejo de serem políticas. Eis o que nos relatou nossa depoente, Daniella Ribeiro:

Como a gente vive numa sociedade muito machista, hoje as coisas mudaram muito, então era difícil pra mim enxergar dentro de casa eu na política, eu sempre achava que ia ser meus irmãos. Uma vez meu irmão era Deputado Estadual e houve a possibilidade... ele recebeu o 
Revista NEP - Núcleo de Estudos Paranaenses, Curitiba, v. 5, n. 2, dez. 2019 Dossiê Oligarquias do Nordeste no Brasil

ISSN: 2447-5548

convite pra ser vice-Governador com Roberto Paulino, ai abriu essa vaga... a gente numa reunião, eu super política ali nos bastidores, ai meu pai disse: então se Aguinaldo for então Pedro você vai ser o nosso candidato a Deputado Estadual. Meu irmão nunca quis saber de política, que injustiça... mas ainda aquela coisa de mulher, como eu ia me atrever naquele instante a dizer que quero... eu tive que adiar um pouco, ter sabedoria pra esperar o momento. (Entrevista com Daniella Ribeiro, 13 de fevereiro de 2017)

A permanência no poder é uma das características dos grupos de tradição política, as oligarquias. Com o passar dos anos, estas que sempre representaram valores conservadores, foram aos poucos incorporando as mulheres ao seu círculo de poder. No momento em que os homens começaram a "faltar", por não poderem mais se candidatar ou simplesmente por não demonstrarem interesse, as mulheres se tornaram opção para dar continuidade a certos nomes e ocupar determinadas cadeiras. É nesse sentido, que é possível pensar a entrada de algumas mulheres no espaço da política, a Senadora Daniella Ribeiro é um desses exemplos. No início, seu nome não era considerado pelo seu pai, o chefe do "clã político", para exercer tal função.

Daniella Ribeiro quando questionada quanto aos motivos e influencias que a fizeram entrar para a política, afirmou ser a vocação e a vontade de ajudar as pessoas o maior incentivo. No entanto, não deixou de destacar o exemplo e prática política de seu pai como um grande incentivo para também desejar fazer parte da política. O meio que mais proporciona a entrada de homens e mulheres na política, tem sido através dos nomes de família e dos grupos oligárquicos. Desse modo, pela característica de perpetuação de um sobrenome nos espaços de poder, é possível categorizar a Senadora como uma representante de tais grupos, que tem sua inserção e trajetória política alicerçada nesses nomes repletos de prestigio e capital político familiar:

\begin{abstract}
Eu gosto muito de lidar com pessoas, de ajudar. Eu tive uma infância quando meu pai era prefeito de Campina Grande e as programações dele eram todas em torno da cidade, tanto com relação a ir ver as obras de Campina Grande como em relação à minha casa sempre cheia de muitas pessoas... Eu participei de várias campanhas dele, envolvia muito desde muito cedo, militando pelo nome dele. Eu sempre gostei muito, gosto do tema, gosto de política, gosto de ver a questão da cidadania, tudo isso faz com que você acabe enveredando para a política. Em relação à minha entrada na política, meu pai ficou meio receoso, pois ele sabe que é um meio muito masculino, machista e como pai ele se preocupava, inclusive de se deparar com alguma situação de alguém falar de mim. Eu disse a ele que não se preocupasse que eu saberia me defender. (Entrevista com Daniella Ribeiro, 13 de fevereiro de 2017)
\end{abstract}

Essa forma de representação política da mulher se mistura com um papel de subordinada, resultante de um processo de submissão de gênero e que a mantém, silenciosamente, ligada à esfera privada. Logo, torna-se interessante analisarmos os casos da inserção da mulher na política como insuficiente para sua completa emancipação. A emancipação feminina no contexto político se consolida quando ela se desliga das forças de dominação que a colocam em segundo plano e que 
insistem em se manter mesmo quando ela passa a ocupar esses espaços de poder. A fala de Daniella buscando o seu empoderamento ao afirmar para o pai não temer as atitudes machistas pois ela sabe se defender, é algo muito positivo, pois cabe a mulher encontrar seu próprio caminho e "armas" para lutar contra o machismo, sem contar com os "braços" do masculino e da família.

Para Avelar (1987), a poderosa família política resolve boa parte dos problemas estruturais, institucionais e individuais relacionados à inclusão da mulher no campo político, na medida em que ela libera, auxilia e apoia a mulher na vida pública. Inicialmente ela é "liberada" de seu espaço "naturalizado", a casa, para permear em outro espaço, o público, a política. Logo depois, ela é "aceita" e "auxiliada" pelo partido e herda as bases políticas de sua família. Ou seja, a via familiar reduz significativamente os obstáculos que surgem para essa mulher que é protegida pela força do homem da família que quase sempre está ao seu redor.

A realidade social da qual a mulher fala, a sua formação pessoal, intelectual, a construção de seus valores, os mecanismos utilizados para adentrar o espaço da política, são fundamentais para se compreender quais as suas pautas de defesa, seus interesses, enfim, quais suas práticas enquanto mulher pública e política.

O meio político, quase que totalmente masculino, se apresenta por vezes para a mulher, como um espaço que a desrespeita e a discrimina, além de instituir uma espécie de cobrança redobrada quanto à capacidade e mérito para fazer parte desse nicho.

A cultura não só política, mas de uma maneira geral, machista e misógina repele uma maior abertura e possibilidade do aumento da representação feminina nos espaços de poder. A ideia naturalizada e socialmente aceita de que a mulher tem maior propensão aos cuidados maternos e do lar, acaba por não a estimular a participar ativamente da vida pública, política e partidária. O peso do poder econômico como um "facilitador" para a entrada na esfera pública e política, é também algo fundamental para se compreender a estruturação da política paraibana e nacional.

As reflexões que se dedicam a análise da presença e participação das mulheres na política e de como a mídia representa a mulher em seus noticiários, (Miguel \& Biroli, 2006 e Paiva, 2008), apontam para a reprodução de estereótipos de gênero. São recorrentes as matérias que identificam, por exemplo, a mulher política a partir de suas características físicas, de sua aparência e do seu modo de se vestir, pondo em segundo plano sua atividade enquanto agente pública e endossando a permanência de papeis sociais tradicionais. Assim, ao iniciar sua trajetória na política Daniella Ribeiro afirmou serem comuns a produção de notícias em torno de seus atributos físicos: 
Revista NEP - Núcleo de Estudos Paranaenses, Curitiba, v. 5, n. 2, dez. 2019 Dossiê Oligarquias do Nordeste no Brasil

ISSN: $2447-5548$

competente, a mais trabalhadora, a que mais trouxe projeto... se voce não tiver cuidado você vira apenas isso, se a mídia pega isso intensivamente, você vira apenas isso, eu lutei muito contra isso... isso me incomodava, quando comecei as reportagens eram todas nesse sentido... deixa isso pra manequim, pra modelo, a gente que trabalha em outras áreas quer ser conhecida pela força, pelo seu trabalho. (Entrevista com Daniella Ribeiro, 13 de fevereiro de 2017)

O julgamento da mulher a partir de sua aparência, do seu modo de se vestir, de falar, de se comportar está presente em todos os segmentos sociais. A mulher é comumente rotulada e classificada como apta ou não para determinados cargos, posições e lugares. Desse modo, ao falar sobre o desrespeito que a mulher sofre nos diversos ambientes sociais, nossa depoente demonstrou acreditar que cabe a mulher fazer certos tipos de concessões e adotar determinadas posturas para que assim, evite passar sobre o crivo dos discursos sociais conservadores. As suas apreensões frente a este fato, corroboram com seu posicionamento de vertente mais tradicional e baseado, sobretudo a sua adesão e convicção religiosa de vertente evangélica:

Se a gente não tiver apoio de marido e filhos, a gente sabe o quanto é difícil... graças a Deus minha vida pessoal sempre foi muito respeitada. Minha família sempre fiz questão que aparecesse durante a campanha, não expondo minha vida pessoal mas todo mundo sabe que eu sou casada, que tenho três filhos, sempre dei muito valor a minha família. Meu marido que me apoia, então ele sempre teve presente quando podia... ele estava do meu lado, em algum evento a noite também ele sempre me acompanhou, esse cuidado que a mulher tem que ter... esse é o tipo de coisa que a gente sofre, tem que ter cuidado com a aparência... a minha postura, a minha forma de vestir... roupa que insinuasse, que é importante a mulher andar bem vestida, o cuidado de se portar bem, então tudo isso já faz parte de mim.. isso ajuda a não ter determinadas coisas. (Entrevista com Daniella Ribeiro, 13 de fevereiro de 2017)

Os questionamentos quanto a competência e capacidade da mulher se fazer presente nos espaços de poder são constantes. A mulher é comumente colocada em teste por uma sociedade machista, sexista, misógina e patriarcal que tenta negar a sua legitimidade em participar da política e atuar com as mesmas condições de igualdade que o homem. Daniella Ribeiro nos relatou uma situação que vivenciou enquanto parlamentar, na Assembleia Legislativa e na qual se sentiu profundamente desrespeitada devido ao seu gênero, ser uma mulher e estar ocupando um espaço socialmente e culturalmente construído para o homem:

Eu vou te dizer uma situação que marcou muito para mim. Essa situação, inclusive, já aconteceu comigo e com outras mulheres políticas. "Agora vamos convidar a deputada, a vereadora, a prefeita fulana de tal para enfeitar a mesa”. Enfeitar a mesa? Enfeitar a mesa é demais, chame um vaso que é melhor. Então nós não estamos lá para enfeitar, estamos lá para dá nossa contribuição com conteúdo. (Entrevista com Daniella Ribeiro, 13 de fevereiro de 2017)

Nesse sentido também, ela relatou sua primeira experiência ao ser eleita para assumir um cargo no legislativo municipal na cidade de Campina Grande. A maneira como o meio de comunicação em questão se referiu a ela, à época Vereadora, reafirma o preconceito que a mulher 
enfrenta na política e a crença em sua objetificação, vista tão somente pelo prisma de sua aparência e de seu corpo, colocando em segundo plano a sua capacidade intelectual e sua competência enquanto sujeito político. Ela ainda reforçou a necessidade da mulher se impor diante tais situações:

Quando fui eleita como Vereadora e um portal da Internet colocou que eu tinha sido eleita para passar batom e pentear o cabelo na Câmara de Vereadores eu achei essa matéria bem pejorativa. Já passei por situações que se não tivermos cuidado, existe certa intimidação. A maioria dos homens são respeitadores e reconhecem o papel e importância da mulher na política, a igualdade de gênero no espaço político. Mas, infelizmente, existem outros que acham que mulher só serve para gritar e é preciso se impor e o respeito é necessário. Não podemos dar o nosso lugar. (Entrevista com Daniella Ribeiro, 13 de fevereiro de 2017)

Daniella Ribeiro entende que uma das maiores dificuldades para que a mulher consiga entrar, participar e se estabelecer no meio da política é a conciliação entre a vida privada e a atividade política, em outras palavras, é saber lidar com a dupla jornada. O homem casado, pai de família que também está na política, não enfrenta com a mesma intensidade esse tipo de dificuldade, exatamente porque as atividades da casa não são entendidas cmo obrigações que devem ser compartilhadas, igualmente, pelo casal, mas cabe a mulher a exercer, exigindo assim, uma tripla jornada de trabalho;

Esse talvez seja o maior desafio para nós mulheres políticas. A agenda política não é programada antecipadamente. Muita coisa acontece de última hora. Então, essa é a maior dificuldade. Quando se tem um planejamento, com uma agenda fixa, ótimo. Mas quando as coisas acontecem de última hora, temos a dificuldade de fazer esse ajuste. A mulher tem muita sabedoria e consegue dar conta disso. Algo que é muito importante é o apoio da família e isso eu tenho. Graças a Deus minha família está ao meu lado, se eles apoiam significa que eles compreendem. Certa vez, minha filha ligou para mim e eu não podia atender, pois eu estava presidindo uma sessão na Câmara de Vereadores e era para dizer que ela tinha passado no vestibular e eu fiquei arrasada, às vezes dá aquela dorzinha. (Entrevista Daniella Ribeiro, 13 de fevereiro de 2017)

A nossa depoente, parece não enxergar com clareza, à situação de submissão e de exploração que sofre a mulher sob a ordem patriarcal vigente no Brasil. Basta ver o seguinte depoimento quando ela relata sobre a divisão de tarefas em sua casa, Daniella afirmou não existir um "sobretrabalho" para ela, pois ela tem em sua casa pessoas que assumem a responsabilidade doméstica que seria por ela executada.

Eu diria que não existe divisão de tarefas determinadas. Eu organizo minha casa, deixo feira arrumada e tenho pessoas em minha casa que me ajudam. Eu tenho três filhos, todos adultos, um já casado inclusive. Existe na minha casa muita compreensão e o apoio do outro. Se alguma tarefa de casa não sai como planejado, existe uma compreensão muito grande. Nós nos ajudamos muito na hora das necessidades. Não existe divisão de tarefas, mas existe muito apoio mútuo. (Entrevista com Daniella Ribeiro, 13 de fevereiro de 2017)

Na verdade, o que nossa depoente não observa é que é necessário o trabalho de outra ou outras mulheres, no caso, empregadas domésticas, para que ela seja "liberada" das atividades de casa. Não 
é um filho ou o marido que assume tais funções, mais o gênero feminino, como se tais atividades, desenvolvidas no espaço do privado, da casa, fossem "naturalmente" uma atribuição do feminino.

Quando instada a pensar sobre políticas públicas, ela mesma traz à tona a noção de um certo essencialismo para o masculino e para o feminino, como se existissem características inatas e naturais para o gênero masculino e para o feminino. Em outras palavras, é como se essas caraterísticas "naturais" aliadas aos "valores culturais", imprimissem olhares diferenciados no sentido de interesses e pautas políticas a variar dependendo do gênero em questão:

\begin{abstract}
Nós mulheres temos a sensibilidade necessária da importância das políticas públicas e para entendê-las. Os homens contribuem, mas eles não compreendem na essência, pois quem vivencia é a mulher. Um exemplo é a creche: uma creche bem organizada possibilita que uma mãe trabalhe. Se o seu filho estuda em uma boa escola, certamente uma mãe trabalha tranquila. Tudo isso são políticas públicas onde a mulher sofre mais diretamente as consequências, mais do que os homens. É preciso ter vocação, o amor, o compromisso, a competência, seja homem ou mulher, essas qualidades são importantes. Eu acho que todos dois contribuem e cada um tem sua inteligência, sensibilidade e perspicácia. Talvez o que diferencie é que o homem tem outro olhar para determinados temas, assim como nós mulheres também temos outros olhares. Essa diversidade, onde cada ser humano é individual que Deus criou para viver em sociedade, enriquece o parlamento e a política como um todo. Um político é um ser que vem da sociedade. É preciso que cada um saiba o que está fazendo para poder andar de cabeça erguida. (Entrevista com Daniella Ribeiro, 13 de fevereiro de 2017)
\end{abstract}

A mulher, a partir do discurso acima descrito, parece ser detentora de uma qualidade ímpar que lhe é atribuída e que também pode ser utilizada no espaço de poder que é o cuidar. O ofício da mulher política é, antes de tudo, cuidar do povo, promovendo qualidade de vida, saúde, segurança através de seu trabalho. É um cuidar coletivo, sem se voltar para si ou para anseios puramente individuais. A sensibilidade da mulher de cuidar do povo tem o mesmo predicado que o cuidar dos filhos e da família que o saber cultural lhes atribuiu.

É nesse sentido o entendimento de Lima, Nascimento e Pontes (2016) que entendem que em virtude da socialização histórica, da abnegação e do cuidado maternal, a mulher ao entrar na política é conduzida à manutenção dessas suas características que lhe foram imbuídas culturalmente, sendo por esse motivo comum identificarmos mulheres atuando na área das causas sociais, voltadas para a assistência e proteção do outro. Essa sua postura remete às qualidades de mãe e de dona-de-casa. Nessa esteira, Miguel e Biroli formulam que:

Há indícios de que as mulheres se ocupam com mais frequência de temas ligados à área social do que aquelas vinculadas diretamente ao controle do Estado e de seus recursos e à distribuição dos postos de exercício de poder (MIGUEL \& BIROLI, 2011, p.80). 
O questionamento feito por esses e outros autores é o de se essa "propensão" à área social seria uma opção, ou justamente uma falta de opção: as mulheres encontrariam nesse nicho o único meio e temas disponíveis para sua atuação no meio político.

Outro ponto a ser observado em relação à necessidade da participação de mulheres na política seria o de que somente elas seriam capazes de dialogar e propor as demandas exigidas pela parcela feminina da sociedade. Sob esse aspecto, as mulheres teriam interesses especiais e legítimos ligados ao gênero. No entanto, Miguel e Biroli (2006) afirmam haver nessa crença um essencialismo subjacente:

Parece que as mulheres, apenas por serem mulheres, terão sempre interesses idênticos. Contra isso, há o fato de que os indivíduos ocupam, ao mesmo tempo, diferentes 'posições de sujeito', cujas pressões são variadas e por vezes, contraditórias. (MIGUEL \& BIROLI, 2006, p. 26).

Mulheres candidatas ou já inseridas na prática política, na forma de um mandato, muitas vezes não são necessariamente comprometidas com a questão feminina ou de uma pauta feminista. Ao acompanhar um pouco da dinâmica da política paraibana, claramente se enxerga o caráter conservador, tradicional e comprometido com determinadas pautas e setores da sociedade. Desse modo, não obstante do que ocorre com uma ínfima parcela de homens que ocupam a prática política (negros, gays, pobres), a presença das mulheres na atividade pública e política passa por esse recorte de conformidade com determinadas imposições históricas e culturais que refletem diretamente na questão de gênero. Estar mais próximo ou mais distante do engendramento proporcionado pelos papeis sócias, pode conferir a essas mulheres maior "facilidade e aptidão" para ocupar e exercer a prática política.

As mulheres oriundas de grupos oligárquicos, tradicionais, de forte capital familiar e político, como a Senadora Daniella Ribeiro, na política representativa, permanecem a reproduzir valores e pautas que corroboram com as práticas desse tipo de grupo. Daniella Ribeiro, nesse sentido, apresenta-se sob uma ótica um pouco mais conservadora devido "a fé proferida", repetidas vezes por ela mesma ressaltada e de importância fundamental na sua conduta enquanto parlamentar. A Senadora, apresenta um discurso mais romantizado da política, colocando sua participação nesse meio como um "desejo vindo de dentro". Ainda que ela represente valores mais tradicionais e tenha tido importante apoio do capital político e familiar, vindo de seu pai, a política também revelou para ela, talvez de maneira menos acentuada, seu caráter machista e preconceituoso no que se refere a presença de mulheres nesse espaço. 
O lugar social, familiar, a formação intelectual e ideológica, religiosa, parecem ser determinantes no que diz respeito a adoção ou não de determinados discursos e pautas, evidenciando que a condição de gênero independe na tomada de decisões. O que se percebe é que, ainda que essas mulheres representem em algumas de suas proposituras e discursos, valores tradicionais quanto ao papel e condição das mulheres, compreende-se que as mulheres são fundamentais no processo de defesa e argumentação das propostas e direitos que se voltem diretamente para elas. O tipo de ação, de projeto, de garantias que será apresentado irá se basear na sua construção enquanto ser social, nos seus valores e ideários. Ainda que as mulheres se configurem sim, como as mais aptas e adequadas à representarem a população feminina nos espaços de poder, a sua formação social, familiar e religiosa, será refletida na sua condução enquanto representante, deixando de fora do debate legislativo e de poder, questões que importam e contemplam outros tipos de mulheres que fogem ao espectro do qual a Senadora Daniella Ribeiro, por exemplo, faz parte.

É sabido também, que na política brasileira, a maior parte da população não se encontra devidamente representada, sobretudo no Parlamento, onde sua composição é quase que por completo preenchida por homens, brancos, de determinada orientação sexual e religiosa e detentor de largo capital financeiro e status social, deixando de fora da representatividade mulheres, negros, a população LGBT, as comunidades ameríndias e quilombolas, pobres e tantos outros segmentos sociais.

Enfim, percebemos que o patriarcado se manifesta como uma forma de educação direcionada a mulher desde sua infância. A cultura exerce um importante papel na formação da personalidade, visão do mundo, e representação social, ou seja, influi para a formação da subjetividade do ser humano. Bastante entrelaçada com a educação, a cultura atrelada ao patriarcado assume o condão de influir no presente e repercutir no futuro. Nesse sentido, a mulher por receber tal educação, é treinada, disciplinada, para cuidar do outro.

A menina vai sendo esculpida ao longo de sua vida. A situação 'submissa' da mulher frente à ocupação de espaços de poder pelo homem está presente desde a sua infância quando, muitas vezes, já tem um destino previamente preparado, especialmente por aquelas famílias fortemente marcadas pela cultura patriarcal e oligárquica. Existe uma construção social em torno da mulher que a obriga a ser mais cuidadora, abnegada, a ter uma visão mais ampla de bem estar.

Não há que se falar em qualquer dado biológico que seja suficiente para diferenciar a capacidade entre meninos e meninas, mas, tão somente, em regras que a educação, a sociedade e a cultura impõem. Dependendo da educação familiar, a mulher desde a infância volta-se para os 
afazeres domésticos e isso intensifica a força do poder masculino, muitas vezes assentado no patriarcado gerando, consequentemente, despreocupação quanto aos outros desejos de vida que não se relacionam com o lar, com a casa.

A "divisão" de atividades incentiva as mulheres a tomarem para si o compromisso do cuidado com os filhos, da educação doméstica, ou seja, de todas as atividades inerentes ao espaço privado. Para Pateman (1993), a família passou por um grande processo de estruturação e transformação para ser vista como é hoje. Antigamente, o contrato de casamento era um contrato de trabalho através do qual tornar-se esposa implicava em tornar-se dona de casa. Logo, ser esposa significava ser alguém que trabalha para o seu marido no lar conjugal.

Por isso, há de se ter o cuidado e de se fazer uma reflexão sobre o papel exercido pela própria família já que ela exerce uma preponderância fundamental de prorrogação da dominação do homem e jugo da mulher, apresentando-se como uma academia que transmite preceitos socioculturais. Sobre a menina e sobre sua formação como mulher, Beauvoir (1960) afirma:

\footnotetext{
Tratam-na como uma boneca viva e recusam-lhe a liberdade; fecha-se assim um círculo vicioso, pois quanto menos exercer sua liberdade para compreender, apreender e descobrir o mundo que a cerca, menos encontrará nele recursos, menos ousará afirmar-se como sujeito; se a encorajassem a isso, ela poderia manifestar a mesma exuberância viva, a mesma curiosidade, o mesmo espírito de iniciativa, a mesma ousadia que um menino (BEAUVOIR, 1960 a, p.22).
}

Ao acompanhar um pouco da dinâmica da política paraibana, claramente se enxerga o caráter conservador, tradicional e comprometido com determinadas pautas e setores da sociedade. Desse modo, não obstante do que ocorre com uma ínfima parcela de homens que ocupam a prática política (negros, gays, pobres), a presença das mulheres na atividade pública e política passa por esse recorte de conformidade com determinadas imposições históricas e culturais que refletem diretamente na questão de gênero. Estar mais próximo ou mais distante do engendramento proporcionado pelos papéis sociais, pode conferir a essas mulheres, maior "facilidade e aptidão" para ocupar e exercer a prática política.

\section{CONSIDERAÇÕES FINAIS}

As mulheres oriundas de grupos oligárquicos tradicionais, de forte capital político familiar, na política representativa, permanecem a reproduzir valores e pautas que corroboram com as práticas desse tipo de grupo. Daniella Ribeiro, nesse sentido, apresenta-se sob uma ótica conservadora devido “a fé proferida", repetidas vezes por ela mesma ressaltada e de importância fundamental na sua 
conduta enquanto parlamentar. Ela apresenta um discurso romantizado da política, colocando sua participação nesse meio como um "desejo vindo de dentro". Ainda que ela represente valores mais tradicionais e tenha tido importante apoio do capital político familiar, vindo de seu pai, a política também revelou para ela, talvez de maneira menos acentuada, seu caráter machista e preconceituoso no que se refere à presença de mulheres nesse espaço.

O lugar social, familiar, a formação intelectual e ideológica, religiosa, são determinantes no que diz respeito a adoção ou não de determinados discursos e pautas, evidenciando que a condição de gênero independe na tomada de decisões.

A presença das mulheres no espaço da política parece se tornar menos socialmente custosa, quando estas advêm de setores e grupos mais conservadores da sociedade. Foi possível perceber na fala de nossa depoente uma posição talvez mais confortável quanto ao tratamento dado à mulher na política. Mesmo estando em conformidade com os valores tradicionais e os papéis culturalmente estabelecidos e aceitos, essas mulheres não deixam de ter uma permanência na vida pública e política, atrelada a questionamentos de gênero e outros tipos de discriminação.

O que se entende é que, ainda que essas mulheres representem em algumas de suas proposituras e discursos, valores tradicionais quanto ao papel e condição das mulheres, compreendese que as mulheres são fundamentais no processo de defesa e argumentação das propostas e direitos que se voltem diretamente para elas. O tipo de ação, de projeto, de garantias que será apresentado, conforme o exposto, ao longo dessas reflexões, irá se basear na sua construção enquanto ser social, nos seus valores e ideários. Ainda que as mulheres se configurem como as mais aptas e adequadas para representarem a população feminina nos espaços de poder, a sua formação social, familiar e religiosa, será refletida na sua condução enquanto representante, deixando de fora do debate legislativo e de poder, questões que importam e contemplam outros tipos de mulheres que fogem ao espectro do qual ela faz parte.

Ser oriunda de um grupo de poder, que possui forte e influente capital político, pode implicar, como a própria Daniella Ribeiro afirmou, um meio mais tranquilo de se inserir na política, já que alguns impedimentos sociais como o econômico e o do próprio prestígio podem ser mais facilmente superados; no entanto, a barreira social e cultural que se impõe às mulheres são para todas, e ainda que de maneiras distintas, recai sobre todas elas.

Pode-se questionar diante de toda essa discussão, o porquê da necessidade das mulheres na política, assim como aos homens, é direito das mulheres se fazerem representadas, é direito das mulheres terem suas apreensões e demandas projetadas, discutidas e aprovadas na forma de lei ou de 
política pública que promovam o bem estar e a emancipação de todas elas, sejam elas aquelas que sofrem violência de gênero, aquelas que reivindicam seu direito à saúde, ao corpo e à escolha da reprodução, ou aquelas que lutam pela construção de mais creches e escolas, pensando na melhoria de sua vida e da sua família.

\section{REFERÊNCIAS BIBLIOGRÁFICAS}

ADILSON FILHO, José. A Cidade Atravessada. Velhos e novos cenários da política belo-jardinense. Recife, Comunigraf Editora, 2009.

BEAUVOIR, Simone. O segundo sexo: a experiência vivida. São Paulo, Difusão europeia do livro, 1960 a.

CARVALHO, José Murilo de. Mandonismo, Coronelismo, Clientelismo: uma discussão conceitual. In: DADOS, Revista de Ciências Sociais, Rio de Janeiro, vol.40, n², 1997.

COSTA, Ana Alice Alcântara. As donas do poder: Mulher e política na Bahia. Salvador, NEIM/UFBA. Assembleia Legislativa da Bahia. 1998.

CHARTIER, Roger. A História ou a leitura do tempo. Belo Horizonte, Autêntica Editora, 2009.

FORTUNATO, Maria Lucinete. O Conceito de Coronelismo e a imagem do coronel: De símbolo a simulacro do poder local. Campina Grande, EDUFCG, 2008.

LIMA, Elizabeth Christina de Andrade. NASCIMENTO, Ana Paula Guedes do. PONTES, Carolina de Moura Cordeiro. A disputa e a sub-representação das mulheres nos espaços de poder: o caso da Assembleia Legislativa da Paraíba. NEP - Núcleo de Estudos Paranaenses da UFPR, v.2, n.2, 2016. GROSSI, Míriam Pillar e MIGUEL, Sônia Malheiros. Transformando a diferença: as mulheres na política. In: Estudos Feministas. Ano 9, 2 semestre 2001.

LEWIN, Linda. Política e Parentela na Paraíba: Um estudo de caso da oligarquia de base familiar. Rio de Janeiro, Record, 1993.

LEMENHE, Maria Auxiliadora. Família, Tradição e Poder: o (caso) dos coronéis. São Paulo: Annablume/Edições UFC, 1995.

MIGUEL, Luis Felipe, BIROLI, Flávia. Gênero e política na mídia brasileira. Disponível em: http://www.mulheres.gov.br/assuntos/poder-e-participacao-politica/referencias/genero-emidia/generoepoliticanamidia.pdf. 2006.

MONTEIRO, José Marciano. A Política como Negócio de Família. Para uma sociologia política das elites e do poder político familiar. São Paulo, LiberArs, 2016. 
PAIVA, Raquel. Política: palavra feminina. Rio de Janeiro, Mauad X. 2008.

PATEMAN, Carole. O Contrato Sexual. Tradução Marta Avancini. Rio de Janeiro, Paz e Terra, 1993.

PINHEIRO, Luana Simões. Vozes Femininas na Política: uma análise sobre mulheres parlamentares no pós-constituinte. Brasília: Secretaria Especial de Políticas para as Mulheres, 2007.

RABAY, Glória. CARVALHO, Maria Eulina Pessoa de. Mulher e Política na Paraíba: História de vida e luta. João Pessoa, Editora Universidade da UFPB. 2010.

RÊGO, André Heráclio do. Família e Coronelismo no Brasil: uma história de poder. São Paulo, A Girafa Editora, 2008.

Recebido em: 30 out. 2019

Aceito em: 26 nov. 2019 